\title{
Internet Self-Efficacy and Visual Search Strategies: The Use of Eye Tracking Technology in the Development of Web-Based Learning Resources
}

\author{
Peter Eachus, Simon Cassidy, Sarah Norgate, \\ Lynne Marrow, and Leah Greene \\ University of Salford, Salford, UK
}

p.eachus@salford.ac.uk, s.cassidy@salford.ac.uk, s.h.norgate@salford.ac.uk, l.marrow@salford.ac.uk, l.greene@salford.ac.uk

\begin{abstract}
Higher Education is increasingly relying on e-learning as a means of providing students with teaching and learning resources. Almost inevitably, this means that students interact with these learning resources through the medium of the computer screen. Although there have been significant advances in the design and implementation of on-line resources, exactly how students interact with these resources is a relatively new field of research. In this study, students were asked to interact with three types of virtual learning environment, i.e. BlackBoard, IngentaConnect and Wikipedia, while their eye movements were scanned and recorded using a Tobii 1750 eye tracking system. The data gathered was analysed dynamically, statistically, and graphically in order to identify search patterns and "hot spots" within the online information source. The data was also correlated with a measure of Internet self-efficacy, the Web User Self-Efficacy scale (WUSE). Preliminary findings suggest that qualitative data obtained in this type of study may prove more useful than quantitative data.
\end{abstract}

Keywords: Eye tracking, Internet self-efficacy, visual search, e-learning

\section{Introduction}

Someone once said that the "eyes are the windows to the soul" but in eye tracking research they may best be considered as a portal to higher cognitive processes. The "camera" analogy that is often used in describing the human visual system is quite misleading. Far from being a passive receptor of visual information, the human eye has already started to process visual stimulation

Material published as part of this publication, either on-line or in print, is copyrighted by the Informing Science Institute. Permission to make digital or paper copy of part or all of these works for personal or classroom use is granted without fee provided that the copies are not made or distributed for profit or commercial advantage AND that copies 1) bear this notice in full and 2) give the full citation on the first page. It is permissible to abstract these works so long as credit is given. To copy in all other cases or to republish or to post on a server or to redistribute to lists requires specific permission and payment of a fee. Contact Publisher@InformingScience.org to request redistribution permission. before passing this information onto higher centres in the brain where it will be processed and meaning extracted.

The distribution of the light sensitive retinal elements, rods and cones over the surface of the retina is not even. The most sensitive region of the retina is approximately $1 \mathrm{~mm}$ across and is densely packed with cones. This is the part of the retina that we use for looking at detailed visual stimulation. In order to 
read a sentence on a page the fovea must be tracked over the words sequentially. Tracking of the fovea is required not only in reading, but in the processing of any visual information where detail is important. Visual information processing is also occurring in the periphery of the retina, but for eye tracking researchers this is of less significance. A crucial question for researchers involved in eye tracking is concerned with what eye tracking can tell us about the way in which information is obtained from visual stimuli before processing at a higher level takes place. For humancomputer interface $(\mathrm{HCI})$ researchers this information is vital for the design of hardware and software that involves people interacting with computer systems.

Eye movement research has a relatively long history with the basic characteristics of eye movements being discovered between 1879 and 1920 (Rayner, 1998). Early research was often quite invasive with eye movements being tracked through devices that were in direct contact with the cornea. The first non-invasive technique was developed by Dodge and Cline in 1901 and used a method that involved reflecting light from the cornea. One of the first studies to examine the role of eye movements in a practical task was that of Tinker et al who in the 1930's looked at the influence of typeface, font size, and page layout on reading speed and patterns of eye movement (Tinker, 1963). At the end of the Second World War, human factors research was becoming increasingly important in the training of military personnel. Fitts, Jones, and Milton (1950) used motion picture cameras to capture the eye movements of pilots as they used the cockpit controls of their aircraft.

A difficulty with eye tracking research up until this time was that the head often had to be constrained to prevent any movement that might confound the eye tracking data. The first head mounted eye tracker to overcome this problem was developed by Hartridge and Thompson (1948) and by 1958 Mackworth and Mackworth had developed a system that could record eye movements superimposed on the visual scene that was being viewed.

The use of eye tracking research in HCI, began in earnest during the 1980's, with the advent of the personal computer. Before this time interaction with computers tended to be via punched cards or teletype and therefore the scope for eye tracking research was minimal. With personal computers came video screens and graphical user interfaces (GUI), thus providing eye tracking researchers with further opportunities.

The 1990's saw greater technological advances with the Internet, email, video conferencing and of course computer games consoles. As the interfaces have become ever more complex, eye tracking research has found a niche in helping to answer questions about usability. How do the visual displays used in these technologies influence the manner in which people are able to interact with them?

\section{Technologies Involved}

The two basic types of eye tracking technology available to researchers are the head mounted systems and those that are independent of the participant, for example, being positioned on the desktop in front of the participant. Most systems rely on the use of infrared light that is reflected from the cornea and the retina in order to generate data that can then be used by the researcher to examine the individual's pattern of eye movements. In modern systems the manufacturers usually provide software that helps with the calibration of the system as well as the data collection. Although modern systems are quite easy to set up and to use, reliability can still be a problem and typically $10 \%-20 \%$ of people cannot be tracked reliably. Spectacles, contact lenses, ambient lighting and even seating arrangements can all cause reliability problems.

As can be seen in Figure 1, head mounted systems, such as this one are produced by Applied Science Laboratories (ASL, http://www.a-s-1.com); they can be quite cumbersome and this can limit the range of possible applications. Lightweight versions of the head mounted systems are 


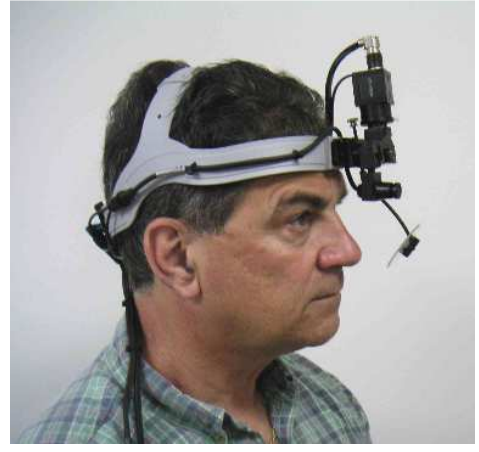

Figure 1: ASL H6 HS

Head Mounted System

(Courtesy of Applied Science Laboratories)

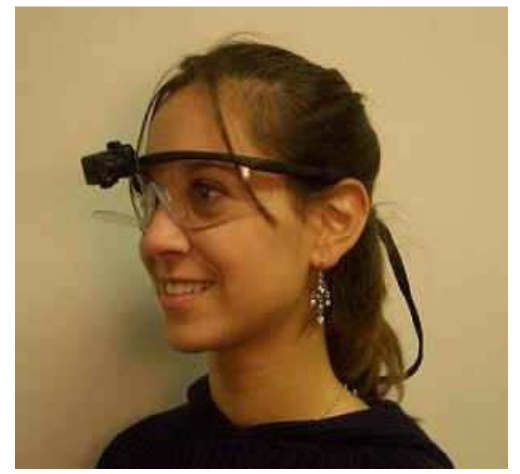

Figure 2 Mobile Eye

(Courtesy of Applied Science Laboratories)

available (Figure 2) and these are particularly useful where the researcher is working with participants who have to be active, e.g playing sport or moving around their environment.

For some applications it is important that the participant can move their head easily and without the constraints of head mounted eye trackers. For example, research with infants would be very difficult using a head mounted system or even one that required head restraint. One system that does offer this degree of freedom is that produced by Tobii (http://www.tobii.com/).

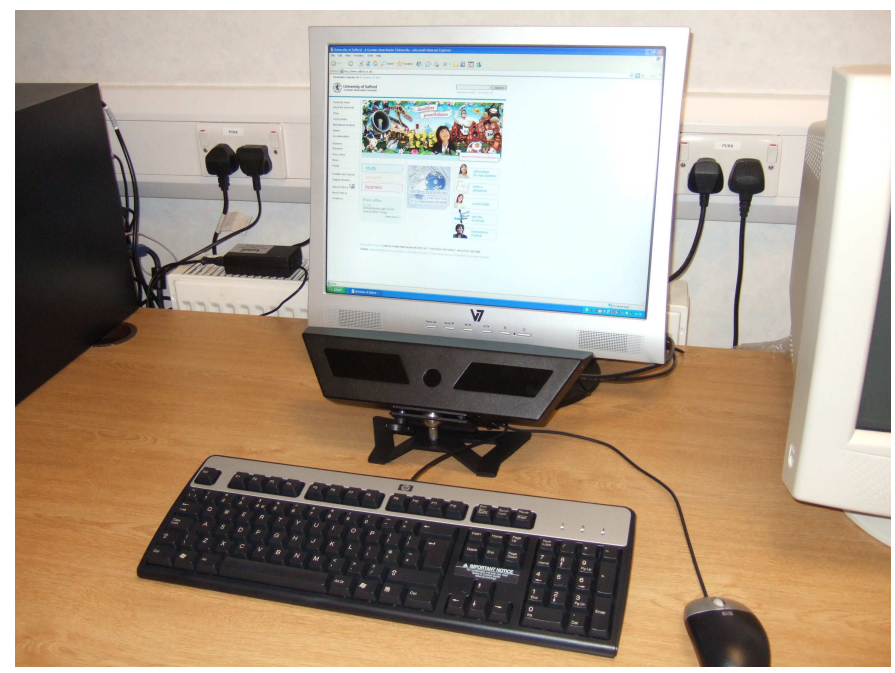

Figure 3 Tobii X50

The Tobii X50 is a relatively small stand alone unit that is positioned just in front of the participant. Calibration is simple using the Clearview software system that is provided with the eye tracker. The Clearview software also deals with the analysis of the data which can be accessed in a variety of formats.

Typically the participant will be positioned in front of the computer screen and if interaction is required, they will be given a keyboard but this isn't a requirement. The visual stimulus may be a website, a picture, or a moving image. Almost any image that can be presented via a computer screen can be used. The X50 uses an infrared light source to monitor eye tracking and this is invisible from the participant's perspective. The participant may be given a specific task to undertake, for example, finding information from an Internet source, or they may be presented with a static image to peruse. It should be noted that if using a keyboard some data may be lost as the 
participant looks down at the keys rather than directly at the screen. The length of a typical session will obviously vary with the task but it may last from a few seconds to several minutes. Researchers should be aware that a voluminous amount of data will be produced with the longer studies.

\section{Eye tracking Metrics}

Most eye tracking systems produce data that can be examined in several different formats to meet the needs of most researchers.

\section{Scan path}

This is probably the most basic form of data representation and is simply a trace of fixation points recorded in real time. This enables researchers to see quite precisely what a participant is looking at as well as the sequence of eye movements over the visual stimulus (Figure 4).

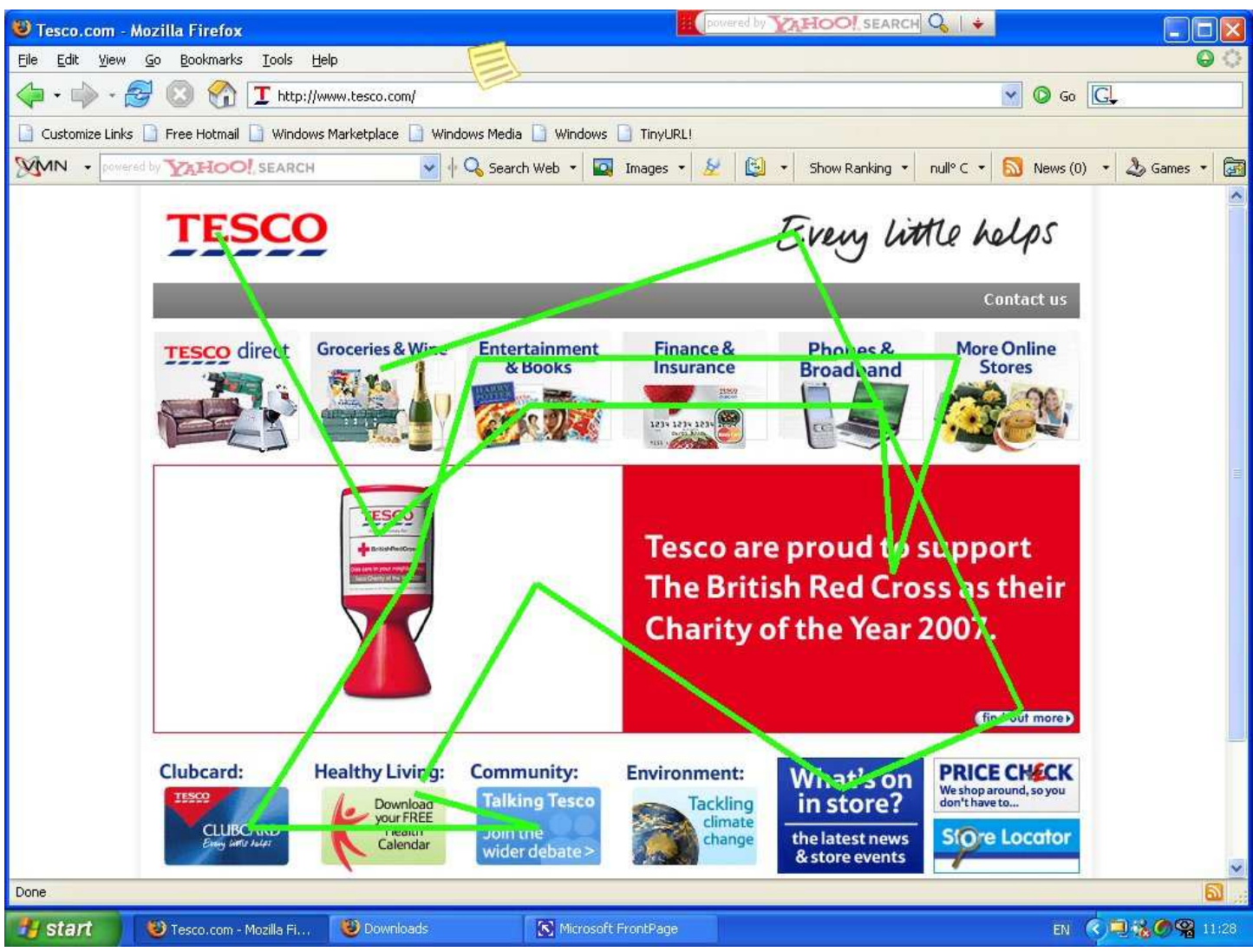

Figure 4: Example of a scan path

\section{Spatial analysis}

If the researcher wants to quantify rather more precisely what the participant is looking at then spatial analysis can be used. In the example shown in Figure 5 the number of fixations on a particular region of the visual stimulus has been converted into "hot spots" where red, or darker areas, indicates a higher number of fixations. 


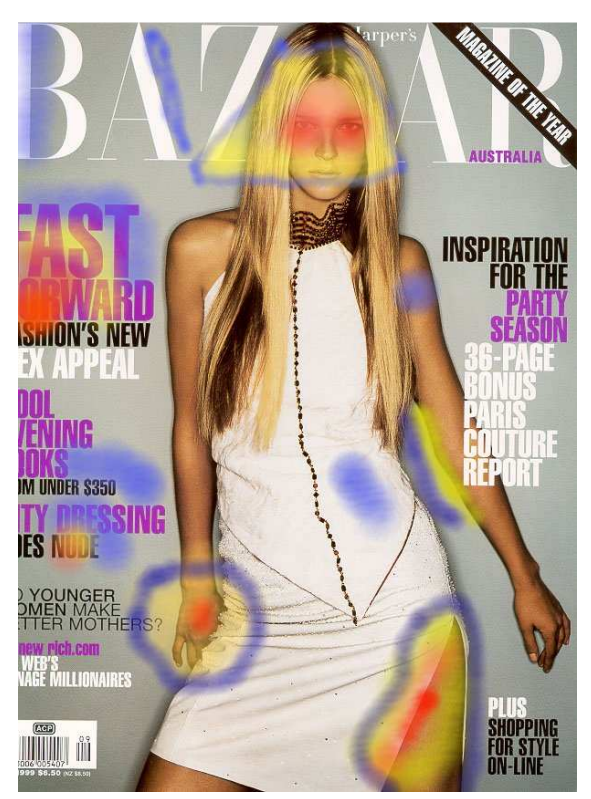

Figure 5 Spatial analysis via "hot spots"

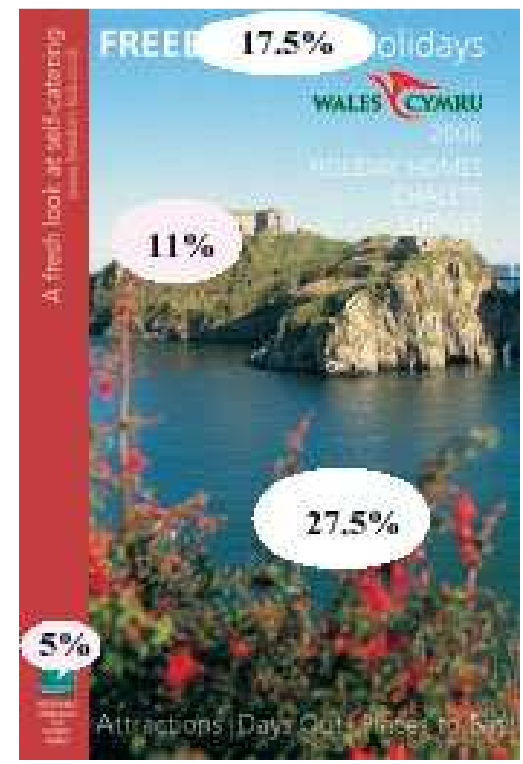

Figure 6 Statistical analysis

\section{Statistical analysis}

The "hot spot" measure described above provides a good qualitative presentation of the data, but if more precise measurements are required then it is possible to measure the proportion of time spent looking at different regions of the visual stimulus. This data can be presented in summary form as in Figure 6, or in terms of actual number and duration of fixations in a particular region of the image. This data can be exported as a text file for further analysis using statistical packages, e.g. SPSS.

\section{Interpretation of Eye Tracking Metrics}

While it might be relatively straightforward to collect the data in whatever format is chosen, the interpretation of the data requires careful thought. The problem for the researcher is how to relate a particular pattern of eye movements to the cognitive activity associated with the visual task. For example, does a long fixation on a particular element of the image indicate that the individual is having difficulty with that element, or that they just find it attractive in someway, or perhaps both in the case of a visual illusion? In eye tracking research "top-down" approaches tend to be driven by theory or the need to test a particular hypothesis. For example cognitive theory might suggest that scanning takes place from left to right and therefore it might be better to place the most important elements of a visual image towards the left. An alternative strategy, the "bottom-up" approach starts by looking at where people fixate and then asks the question why do they look more at one particular element of the image rather than another? The two approaches are not mutually exclusive, indeed an effective strategy might be to begin without preconceived notions using a "bottom-up" approach, and then to formulate hypotheses based on these observations and what is known from cognitive theory.

From previous research it is possible to suggest what the psychological importance of different metrics might be:

Fixation Number: This appears to be related to search efficiency (Goldberg \& Kotval, 1998). Large numbers of fixations probably indicate that the participant is searching for something that they are having difficulty locating, possibly because of poor design of the visual stimulus. Jacob 
and Karn (2003) suggest that the number of fixations on an element should reflect the importance of that element.

Gaze: The proportion of time spent looking at a particular element of the visual stimulus is generally seen as an indication of the importance of that element (Jacob \& Karn 2003). Gaze duration may be measured as eye fixation time on target, or it may be made up of a number of different fixations on the target.

Area of Interest: AOI analysis is used where the researcher wants to quantify gaze data within a defined region of the visual stimulus. For example, in the case of a web page, the researcher might be interested in how often or for how long the participant looks at a region of the web page that the designers have designated of high importance. Fitts et al. (1950) have shown that gazes on a particular AOI will be longer if the participant has difficulty extracting meaning from that region of the stimulus.

Scan Path: The scan path is made up of a sequence of fixations as shown in Figure 4. As well as the overall pattern of fixations, researchers might be interested in the direction of scan path, e.g. top/bottom, left/right etc, or they may be interested in the scan path duration or scan path length.

Time to first fixation: Where participants are required to identify a particular element in the visual stimulus, the time to first fixation on that element can be a useful measure of efficiency of search strategy or the "attention-getting" properties of the element.

\section{Usability Studies}

The purpose of the studies described below was to examine the feasibility of using eye tracking technology in the evaluation of the usabilty of e-learning web sites, specifically, BlackBoard virtual learning environment (Figure 7), IngentaConnect, the online journal database (Figure 8), and Wikipedia the online encyclopedia (Figure 9).

In addition, it was tentatively hypothesised that there would be a relationship between Internet self-efficacy, as measured by the Web User Self-Efficacy scale (WUSE), (Eachus \& Cassidy, 2006) and the eye-tracking metrics. Internet self-efficacy is a measure of how confident a person feels about their ability to interact with the Internet. The WUSE scale measures this in terms of four constructs: Information Provision, Information Retrieval, Communications, and Internet Technology. Adding the scores obtained on these constructs provides an overall measure of Internet self-efficacy, the WUSE score. It was tentatively predicted that there may be a relationship between the way a person uses their visual system to scan web pages and this measure of Internet self-efficacy.

\section{Sampling}

At the start of each academic year students are routinely asked to complete the WUSE scale in order that their Internet Self-Efficacy may be evaluated to give academic staff some indication of how students are likely to cope with e-learning environments. All students who completed this scale were invited to take part in the study.

\section{Procedure}

A double blind randomised procedure was used with neither the participant nor the researcher knowing the participant's WUSE score. Participants were seated in front of a PC screen with a mouse available for interaction with the on-screen environment. The Tobii X50 eye tracker was positioned, unobtrusively, between the participant and the PC screen (see Figure 3). The calibration procedure requires the participant to watch the screen as a series of circles appear and disappear in each corner and in the centre of the screen. The ClearView software then provides a visual 
guide to the success of the calibration. If there are any problems the calibration process is repeated. This calibration information can be recorded for each participant, which means that the calibration procedure doesn't have to be repeated if the same participant is being used in a further trial. Following calibration, the researcher set the parameters for the session, e.g. how long the session was to last, what type of visual stimulus was to be used and where this stimulus could be found; in the case of website a URL could be specified as a location. Once the session began, eye tracking and data recording occurred automatically as the participant undertook the given task. The eye tracking ceased once the predetermined time interval was reached. During the task, the participant was not aware of the eye tracking, they were not aware of the infrared light that was being reflected from their eyes and there was nothing on the screen to indicate that eye tracking was occurring

In this feasibility study participants were presented with tasks that required them to interact with three web based learning resources, specifically, the Blackboard virtual learning environment, IngentaConnect, an academic journal database, and Wikipedia an online encyclopedia. For the Blackboard trial, participants were asked to spend ten minutes examining online learning materials dealing with "Drugs and Behaviour". In order to motivate participants they were informed that at the end of the ten minutes they would be asked to complete a simple questionnaire dealing with the content and the usability aspects of the materials. In the second task they were asked to use IngentaConnect to find journal articles dealing with learning theory, and for the Wikipedia task they were asked to find out for what B.F. Skinner was best known. None of these tasks were particularly difficult; their main purpose was to provide a vehicle through which the participant could interact with an e-learning resource while eye tracking data was collected. The second two tasks lasted no more than 2 minutes and were terminated once the participant had achieved the task goal.

\section{Results and Evaluation}

The data collected via the WUSE scale provided an overall sample of $N=146$. The WUSE scale measures levels of Internet Self-Efficacy on four subscales: Information Retrieval, Information Provision, Communication, and Internet Technology. Summing the scores on these four subscales provides a WUSE total score, i.e. an overall measure of Internet Self-Efficacy. This was the measure used in this study. Descriptive statistics and the gender split are shown in Table 1.

Table 1: Descriptive Statistics, Web User Self Efficacy Scores

\begin{tabular}{|l|l|l|l|l|l|}
\hline & \multicolumn{1}{|c|}{$\mathbf{N}$} & \multicolumn{1}{|c|}{ Minimum } & \multicolumn{1}{c|}{ Maximum } & \multicolumn{1}{c|}{ Mean } & \multicolumn{1}{c|}{ Std Deviation } \\
\hline WUSE & 146 & 71.00 & 175.00 & 128.93 & 22.32 \\
\hline Males & 15 & 95.00 & 175.00 & 144.86 & 24.92 \\
\hline Females & 129 & 71.00 & 173.00 & 127.10 & 21.52 \\
\hline
\end{tabular}

The difference in WUSE score between males and females was found to be statistically significant $(\mathrm{t}=-3.415, \mathrm{df}=142, \mathrm{p}<0.001$, effect size $=0.81)$. This gender difference in Internet SelfEfficacy is consistent with previous findings (Eachus and Cassidy, 2006).

Following the data collection the ClearView software provides the researcher with several options for data processing. Qualitative data e.g. scan path, fixation points and hot spots are immediately available and it is also possible to export the data for further processing, if required. A time line, number and duration of fixation and X Y coordinates of the left and right eye can be exported as a text file that can then be imported into data processing software, e.g. SPSS or Excel. Scan path data can also be exported as a video (AVI) file for further observation. 
For all three tasks, eye tracking data was successfully recorded, though the quality of that data was variable. Scan path data was recorded accurately for all three tasks and could be played back easily using either the ClearView software, or via an exported AVI file. As was expected, data was occasionally lost when the participant looked down at the mouse but the eye tracker was able to resume eye tracking as soon as the participant looked back at the screen. Examples of the data collected are shown in Figures 7, 8, and 9.

The data collection and analysis was most problematic where changes in the visual image occur, for example, with Flash animations, pop-ups or even when moving from one web page to another. Under these circumstances attempting to view fixation data or hot spots invariably resulted in a blank screen. The explanation for his appears to be that the ClearView software records data continuously and doesn't discriminate between one web page and the next or even between a web

Tools
Announcements
Calendar
Tasks
Send E-mail
Personal Information
How to change your
password

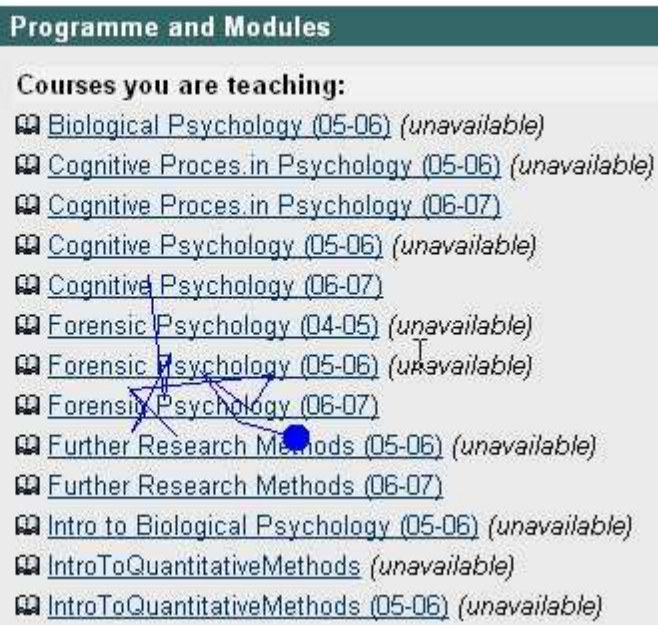

\section{Figure 7 Scan Path (BlackBoard VLE)}

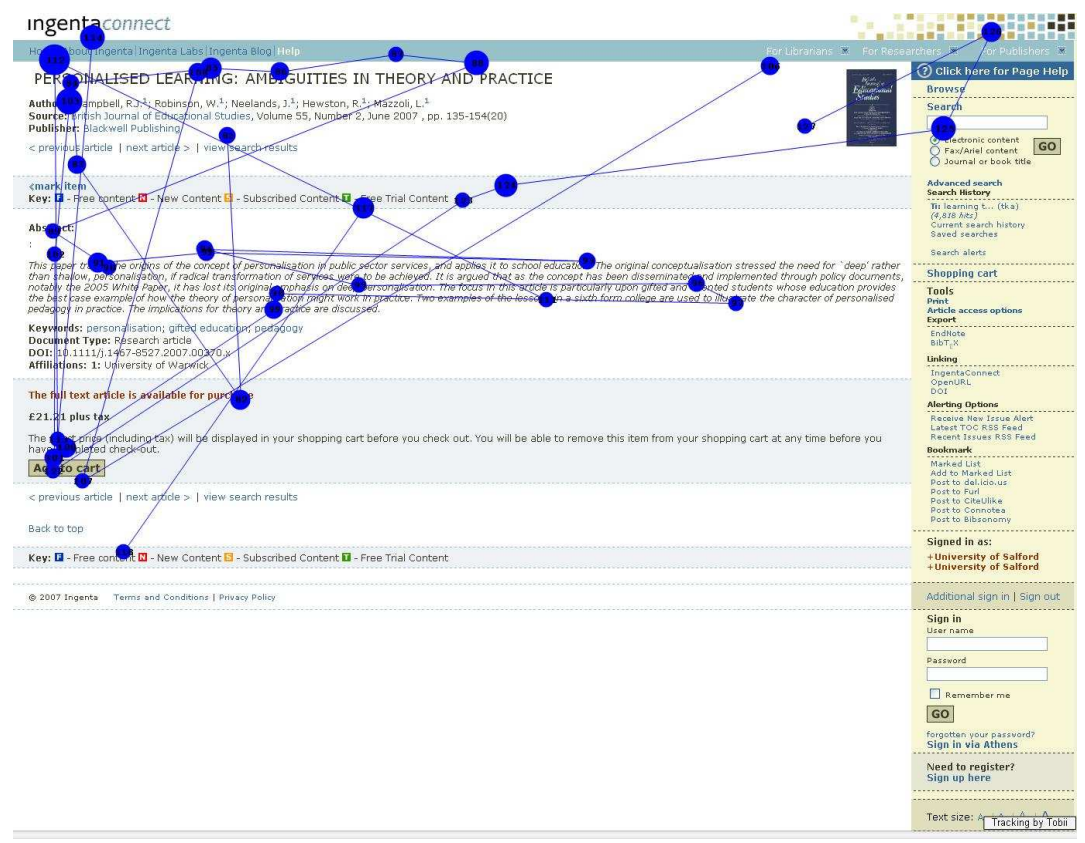

Figure 8 Gaze Plot (IngentaConnect) 


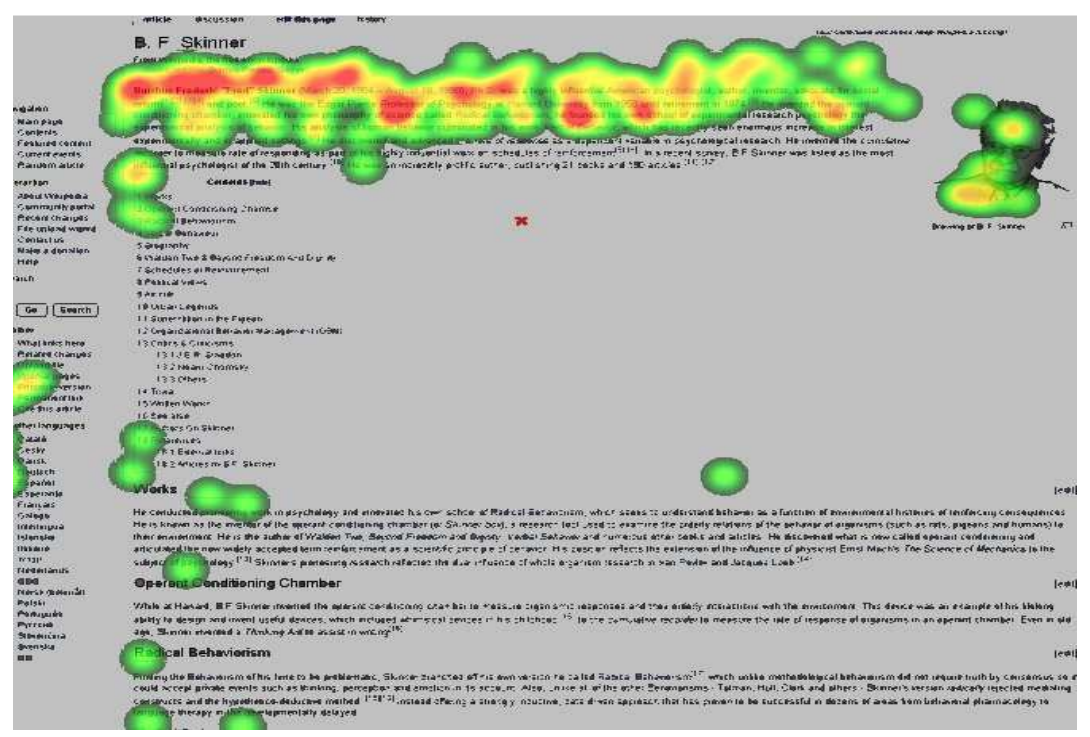

Figure 9 Hot Spots (Wikipedia)

page with an animation and the same page without animation. Fixation data and hot spots extract the data for their plotting from the X Y co-ordinates of each eye as detected by the eye tracker. The X Y co-ordinates are, in a sense, static even though the web page might change. If all the recorded data was plotted then a very confused picture would emerge with, in effect, eye tracking data from different web pages being superimposed on each other. Fortunately Tobii, the manufacturers of this system, have developed a tool within the ClearView software that can help with this problem. The Scene Tool enables the researcher to view a recording of the visual stimulus, including changes to web pages, and the researcher can then identify and mark on the time line where these changes occur. The ClearView software then treats the time between one mark and the next as a single page, and thus fixation and hot-spot data can now be displayed. What is really required is a dynamic fixation and hot spot display system that would actually change as the scene being viewed changes. Unfortunately at present this level of sophistication does not appear to be available.

Tobii suggests that data recording problems can arise if the participant is wearing spectacles, especially bifocals or contact lenses. In this study one of the participants wore varifocal spectacles, but this didn't appear to interfere with the performance of the eye tracker.

In order to examine any possible relationship between Internet Self-Efficacy, as measured by WUSE scores, and the eye tracking metrics, participants were divided into two groups: those who scored +1 standard deviation above the mean WUSE score and those who scored -1 standard deviation below this mean. In this exploratory study it was predicted that there would be differences in eye tracking metrics when these two groups were compared. Although there does appear to be significant variation between individuals (see Table 2) in the metric data obtained, preliminary analysis, using a t-test, has failed to identify consistent differences that would support this hypothesis. Similarly it was predicted that duration of fixation would be related to Internet SelfEfficacy, a Spearman Rank Order correlations failed to find any statistically significant relationship. 
Table 2: Examples of variation in eye tracking metrics

\begin{tabular}{|l|l|l|l|l|l|}
\hline Participant & $\begin{array}{l}\text { Mean } \\
\text { fixations }\end{array}$ & $\begin{array}{l}\text { Mean } \\
\text { Duration }\end{array}$ & Xplot & Yplot & WUSE \\
\hline A & 930 & 285.75 & 681.36 & 480.39 & 175 \\
\hline B & 349 & 144.4 & 696.35 & 408.35 & 102 \\
\hline C & 780 & 296.32 & 694.21 & 427.85 & 151 \\
\hline D & 857 & 225.02 & 651.73 & 397.55 & 116 \\
\hline
\end{tabular}

Table 2 illustrates some of the quantitative data that it is possible to generate using this eye tracking technology. This data was collected over a ten minute period while a participant interacted with a web based learning resource (BlackBoard VLE). A fixation is defined as an interval of time (set at 100 milliseconds) during which the eye doesn't move. Thus, in the data above, it can be seen that during the ten minute period Participant A recorded 930 fixations and the mean duration for each of these was 285.75 milliseconds. This varies considerably from Participant B who had a mean number of fixations of 349 , with a mean duration of 144.4 milliseconds. It can also be seen that these two participants also differ considerably in terms of Internet Self-Efficacy (WUSE). Unfortunately, this preliminary data does not allow us to generalise this finding.

The Xploy and Yplot data is presented to give an indication of how it is possible to quantify the mean position of fixation during the ten minute interaction. This data is recorded in pixels with a screen resolution set at $1400 \times 1050$. In this particular example this data is only of limited use but if a designer wanted to know if a particular region of the screen was the focus of attention, then these measurements could answer that question precisely. It should be noted that the data presented in Table 2 represents the cumulative data over the ten minute period and this represents anything between several hundred and several thousand data points. Thus the data could be analysed over any period of time that might be required by the researcher.

\section{Discussion}

The purpose of this study was twofold: first to examine the feasibility of using eye-tracking technologies in the development of e-learning resources, and second to attempt to quantitatively analyze the relationship between eye-tracking and Internet Self-Efficacy. The findings have shown that from a qualitative perspective, eye-tracking is a useful technology for the development of learning materials that are to be presented via the Internet. Scan path, gaze plot and hot spot analysis provide useful qualitative data for the designer and researcher. What has proved more of a problem is the demonstration of a measurable quantitative relationship between eye-tracking strategies of individuals and their measured Internet Self-Efficacy. The main problem appears to be in understanding what the eye-tracking metrics actually signify. If a person only looks briefly at a screen, does this indicate that they have rapidly absorbed the information as might be expected of someone with high Internet Self-Efficacy? Or is the observed eye-tracking strategy more likely to be associated with a person who has difficulty with the material presented and has therefore largely ignored it? Eye-tracking metrics like number of fixations or the time spent looking at a particular part of the screen may or may not be associated with Internet Self-Efficacy. Further research might gain from using a "think aloud" strategy during which participants verbalise what they are looking at and why. The combination of qualitative and quantitative methods, coupled with the identification of appropriate eye-tracking metrics, may prove more fruitful in the development of e-learning resources. 


\section{Conclusion}

This study has demonstrated the feasibility of using an eye tracking system to record patterns of eye movements while participants interact with e-learning resources. The data produced appears to be reliable, valid and has a degree of sensitivity that would meet the needs of most researchers. The data produced by the Tobii X50 system and the ClearView software is available in a variety of formats, and it can be used to describe the interaction between participant and e-learning resource in both qualitative and quantitative terms. However, relating the data collected, to the cognitive processing of information and psychological constructs, like self-efficacy, may prove more problematic.

\section{References}

Dodge, R., \& Cline, T. S. (1901). The angle velocity of eye movements. Psychological Review, 8, 145-157.

Eachus, P., \& Cassidy, S. (2006). Development of the Web Users Self-Efficacy Scale (WUSE). Issues in Informing Science and Information Technology, 3, 199-209. Retrieved from http://informingscience.org/proceedings/InSITE2006/IISITEach219.pdf

Fitts, P. M., Jones, R. E., \& Milton, J. L. (1950). Eye movements of aircraft pilots during instrumentlanding approaches. Aeronautical Engineering Review, 9(2), 24-29.

Goldberg, J. H., \& Kotval, X. P. (1998). Eye movement-based evaluation of the computer interface. In S. K. Kumar (Ed.), Advances in occupational ergonomics and safety (pp. 529-532). Amsterdam.

Hartridge, H., \& Thompson, L.C. (1948). Methods of investigating eye movements. British Journal of Ophthalmology, 32, 581-591.

Jacob, K. J., \& Karn, K. S. (2003). Commentary on Section 4. Eye tracking in human-computer interaction and usability research: ready to deliver the promises. In J. Hyona, R. Radach, \& H. Deubel (Eds.), The mind's eyes: Cognitive and applied aspects of eye movements. Oxford: Elsivier Science.

Mackworth, J. F., \& Mackworth, N. H. (1958). Eye fixations recorded on changing visual scenes by television eye-marker. Journal of Optical Society of America, 52, 713-716.

Rayner, K. (1998). Eye movements in reading and information processing: 20 years of research. Psychological Bulletin, 124(3), 372-422.

Tinker, M. A. (1963). Legibility of print. Ames, Iowa State University Press

\section{Biographies}

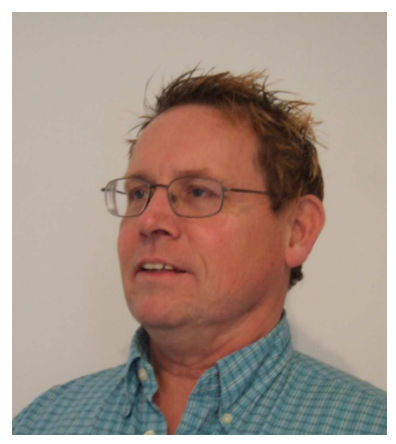

Peter Eachus. My main interests are the psychological aspects of computer and Internet use, specifically the part played by self-efficacy in determining how students in higher education make use of online learning resources. I also have research interests in robotics and the psychology of tourism. 


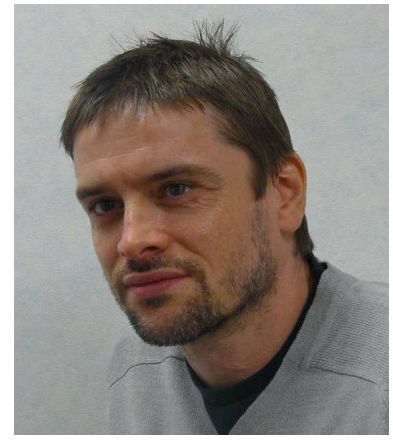

Simon Cassidy. My main interests are in social-cognitive theory and its application to health, education and performance. I am also researching the impact of new technologies, especially the Internet and use of mobile phones on human performance and functioning.

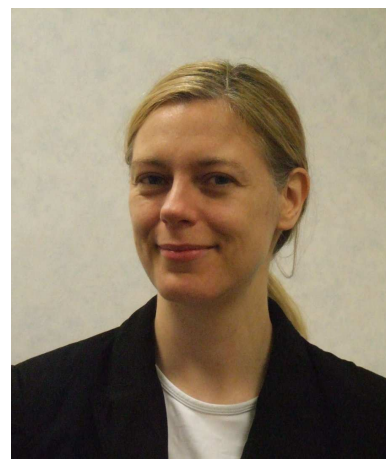

Sarah Norgate. My main interest is in applying mainstream theories of developmental psychology to clinical populations (e.g. children with visual problems) and contexts (e.g. hospitals). I critique molecular genetic lines of enquiry to the study of certain behaviours (e.g. IQ).

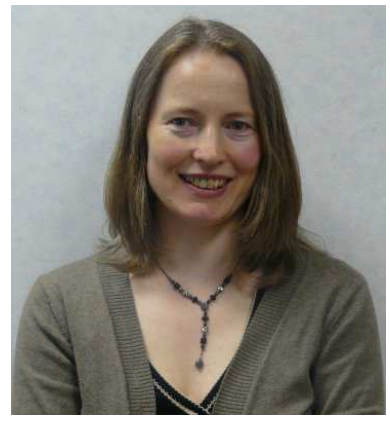

Lynne Marrow. My main interests are focused on aspects of the brain's dopamine systems and I have researched and published in the areas of movement disorders and schizophrenia, depression, the reward systems, substance misuse and aggression. I also have an interest in the use of the Internet as an educational tool.

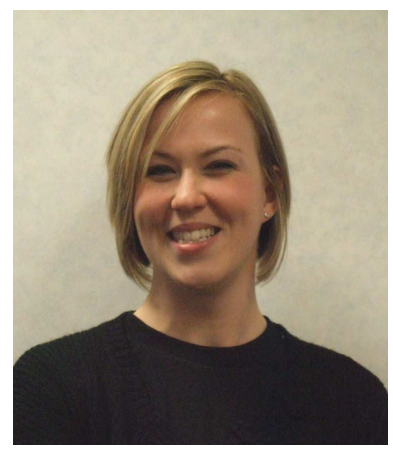

Leah Greene. I am the technician for the School of Community, Health Sciences and Social Care. Within the Directorate of Psychology I support staff in practical/experimental aspects of their module delivery. I also have an important role in supporting students with technical issues concerning their dissertations. 